\title{
Behavioral and Biological Associations
}

National Cancer Institute

\section{Source}

National Cancer Institute. Behavioral and Biological Associations. NCI Thesaurus. Code C15995.

The basic relationships between biological and behavioral factors and/or their potential relationship to prevention and/or cessation interventions. 